\title{
Mucin-secreting neoplastic polyp: a unique endoscopic presentation of early colon cancer
}
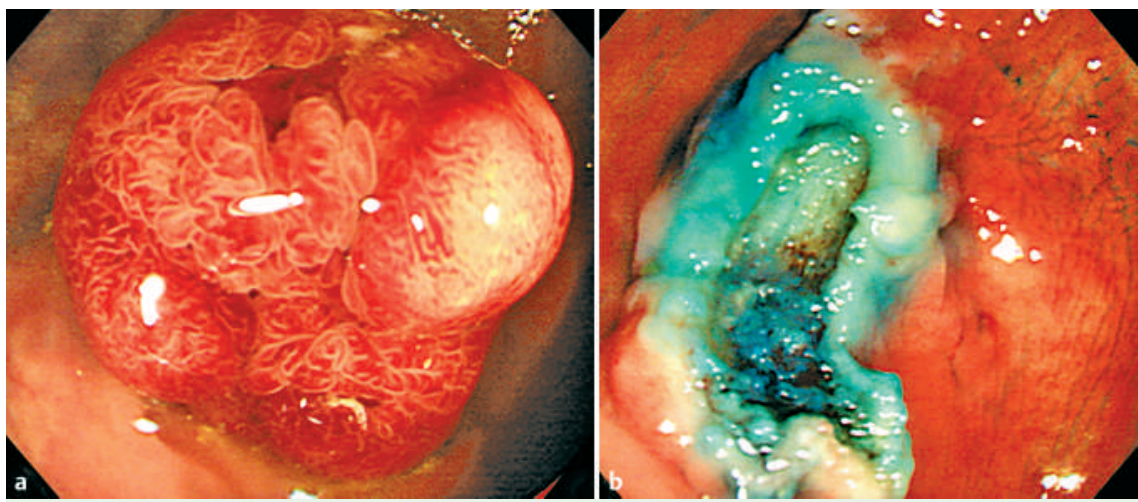

Figure 1 Colonoscopy showed a protruding polyp, $25 \mathrm{~mm}$ in diameter, at the hepatic flexure. a The polyp was reddish and showed characteristic mucin at its apex, suggesting its secretion from within the polyp. b A jelly-like substance, similar to the mucin at the polyp apex, was also seen at the resection site of this polyp.

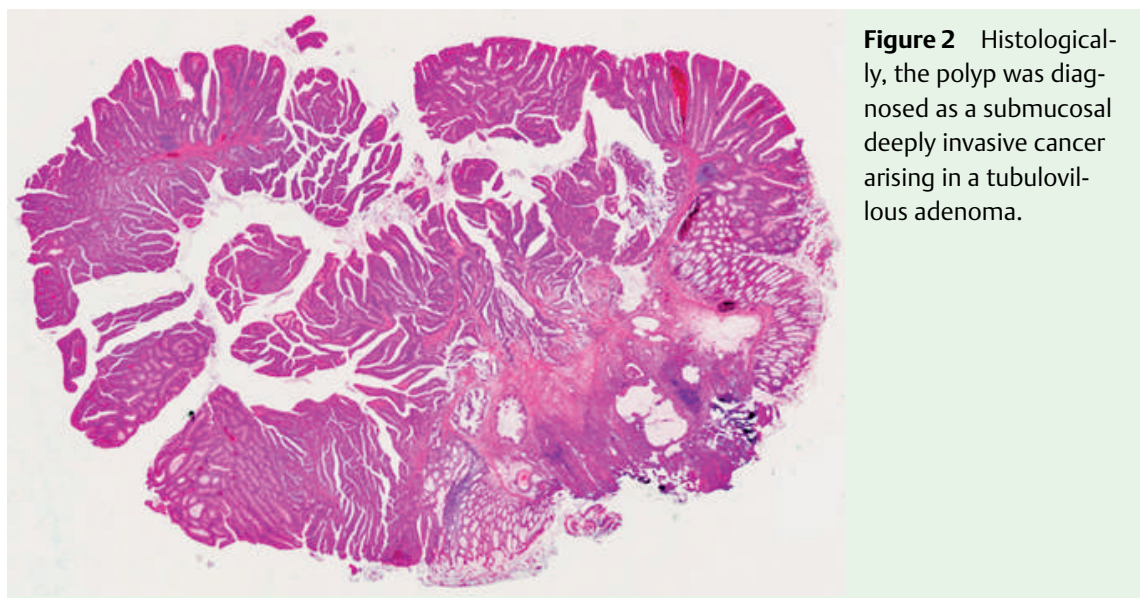

A 73-year-old man was referred to our hospital to undergo polypectomy. Colonoscopy showed a protruding polyp, $25 \mathrm{~mm}$ in diameter, at the hepatic flexure. ( $\bullet$ Figure 1 a). The polyp was reddish and showed characteristic mucin at its apex, suggesting secretion from within the polyp. Magnified chromoendoscopy with $0.4 \%$ indigo carmine dye demonstrated a type IV pit pattern over the entire polyp surface, suggestive of tubulovillous or villous adenoma [1]. The polyp was removed en bloc by endoscopic mucosal resection and, interestingly, a jelly-like substance, similar to the mucin at the polyp apex, was also seen at the resection site ( Figure $1 \mathbf{b}$ ). Surprisingly, the polyp was diagnosed histologically as a submucosal deeply invasive cancer arising in a tubulovillous adenoma ( $\bullet$ Figure 2 ). The invasive cancer consisted mainly of moderately differentiated adenocarcinoma with mucinous carcinoma in part. A cross-sectional view of the polyp showed that the invasive cancer was totally covered by tubulovillous adenoma, making it impossible to diagnose the invasive cancer on the basis of the surface pit pattern $[2,3]$. Interestingly, the mucinous carcinoma was connected to the top and the bottom of the resected lesion, appearing endoscopically as mucinous and jelly-like before and after resection. As the vertical margin was positive for cancer, additional surgical resection was performed with curative intent. No locally residual tumor or lymph node metastasis was detected in the surgically resected specimens.

\section{Acknowledgement \\ $\nabla$}

This work was supported in part by the Grant-in-Aid for Cancer Research (18S-2) from the Ministry of Labour and Welfare.

Endoscopy_UCTN_Code_CCL_1AD_2AC

K. Fu ${ }^{1,2}$, T. Ishikawa², S. Igarashi ${ }^{3}$, Y. Tsuura $^{3}$, K. Hirabayashi ${ }^{3}$, Y. Kaji

1 Department of Radiology, Dokkyo University School of Medicine, Tochigi, Japan

2 Department of Diagnostic Imaging, Division of Endoscopy, Tochigi Cancer Center Hospital, Tochigi, Japan

${ }^{3}$ Department of Pathology, Tochigi Cancer Center Hospital, Tochigi, Japan

\section{References}

1 Kudo S, Hirota S, Nakajima Tet al. Colorectal tumours and pit pattern. J Clin Pathol 1994; 47: $880-885$

2 Fujii T, Hasegawa RT, Saitoh Yet al. Chromoscopy during colonoscopy. Endoscopy 2001; 33: $1036-1041$

3 Kato S, Fujii T, Koba I et al. Assessment of colorectal lesions using magnifying colonoscopy and mucosal dye spraying: can significant lesions be distinguished? Endoscopy $2001 ; 33: 306-310$

Bibliography

DOI 10.1055/s-2007-966107

Endoscopy 2007; 39: E201

(c) Georg Thieme Verlag KG Stuttgart · New York . ISSN 0013-726X

Corresponding author

\section{K. Fu, MD}

Department of Radiology

Dokkyo University School of Medicine

880 Kitakobayashi

Mibu, Shimotuga

Tochigi 321-0193,

Japan

Fax: +81-1-282-86-5678

fukuangi@hotmail.com 